равнительная характеристика результатов применения фракционного фототермолиза в области кожи шеи у женщин в разных возрастных группах



1 Санкт-Петербургский институт красоты

192012, Санкт-Петербург, ул. Савушкина, дом 8, корпус 2

2 ГБОУ ВПО «Санкт-Петербургский государственный медицинский университет им. академика И.П. Павлова» Минздрава России

197022, Санкт-Петербург, ул. Льва Толстого, д. 6/8

\begin{abstract}
Цель исследования. Научное обоснование применения фракционного фототермолиза для коррекции возрастных изменений кожи шеи у женщин в различных возрастных группах.

Материал и методы. Выполнено сравнительное исследование результатов процедуры фракционного фрототермолиза (ФФ) у 60 женщин разных возрастных групп с целью коррекции инволюционных изменений в области кожи шеи (1-я группа — 40-49 лет; 2-я группа — 50-60 лет). Исследовались увлажненность, гладкость (рельеф) кожи, ширина устьев сально-волосяного аппарата, выраженность пигментации, глубина и ширина морщин до процедуры, через 1 нед. и 1 мес. после процедуры.

Результаты. Через 1 нед. ФФ в большей степени повлиял на все изученные функциональные параметры кожи у лиц 2-й возрастной группы по сравнению с 1-й группой. Отмечено уменьшение увлажненности, гладкости кожи, увеличение ширины, глубины морщин, ширины пор и пигментации. Через 1 мес. позитивная динамика показателей гладкости, ширины морщин во 2-й группе была достоверно более выраженной $\left(p<10^{-8} ; p<10^{-7}\right)$, чем в 1-й группе $\left(p=0,002 ; p<10^{-5}\right)$. Увлажненность кожи, ширина устьев сально-волосяного аппарата, пигментация и глубина морщин изменились более значимо у пациенток 1 -й группы $\left(p<10^{-7} ; p=0,001 ; p<10^{-5} ; p<10^{-8}\right)$.

Заключение. Функциональные параметры кожи пациенток 1-й группы ухудшаются менее значимо через 1 нед. после процедуры ФФ в сравнении со 2-й группой. Через 1 мес. после ФФ для пациенток 1-й группы характерно более значимое улучшение показателей увлажненности, ширины сально-волосяного аппарата, глубины морщин и пигментации, а для пациенток 2-й группы - показателей гладкости и ширины морщин.

Выявленные различия в динамике показателей состояния кожи в разных возрастных подгруппах следует учитывать при планировании эстетических результатов процедуры ФФ.
\end{abstract}

Ключевые слова: инволюционные изменения кожи шеи; неинвазивная функциональная диагностика; лазерная дермабразия.

Контактная информация: vkirsanova@yandex.ru. Вестник дерматологии и венерологии 2014; (4): 94_100. 


\title{
omparative characteristics of the results
} of fractional photothermolysis used for neck skin
of women in different age groups

\author{
L.V. Kirsanova ${ }^{1}$, Ye.R. Araviyskaya², Ye.V. Sokolovsky², G.N. Sokolov², A.I. Bogatenkov ${ }^{1}$
}

${ }^{1}$ St.Petersburg Institute of beauty

Savushkina str., 8, buil 2, St. Petersburg, 192012, Russia

2 Pavlov State Medical University of St. Peterburg

L. Tolstogo str., 6—8, Saint-Petersburg, 197022, Russia

The purpose of this research is scientific rationale for fractional photothermolysis usage to correct age-related changes of neck skin of women in different age groups.

Materials and Methods. A comparative study of the results for fractional photothermolysis (FP) treatment in order to correct involutional changes in neck skin of 60 women in different age groups has been carried out (first group — 40—49 years old, second group - 50-60 years old). Skin moisture, its smoothness (relief), the width of the mouths of the pilosebaceous unit, the severity of pigmentation, the depth and width of wrinkles before the treatment, 1 week after and 1 month after the procedure have been investigated.

Main results. After a week of having FP it affected all investigated functional skin parameters more in the 2nd age group than in the 1st one. Decreasing in moisture and smoothness of the skin, increasing the width and the depth of wrinkles, pores and pigmentation width have been marked. In one month there was more significant positive dynamics in parameters of smoothness, wrinkles width in the 2nd group $\left(p<10^{-8}, p<10^{-7}\right)$ than in the 1 st group $\left(p=0.002, p<10^{-5}\right)$. Hydration of the skin, the width of the mouths of the pilosebaceous unit, the depth of wrinkles and pigmentation changed more significantly among patients in group $1\left(p<10^{-7}, p=0.001, p<10^{-5}, p<10^{-8}\right)$.

Conclusion. Skin functional parameters of patients from the first group deteriorated significantly less in comparison with the second group one week after PF procedure was carried out. 1 month after the 1st group is indicated with significant improvement in moisture, the width of the pilosebaceous unit, the depth of wrinkles and pigmentation, and the 2nd group is indicated with improvement of smoothness and width of wrinkles.

The differences discovered in skin condition dynamics in different age groups should be considered when planning the aesthetic outcome of FP procedure.

Key words: incidence of sexually transmitted infections and skin disorders, bed capacity of dermatovenereological medical organizations, bed rates, statistical data.

Corresponding author: vkirsanova@yandex.ru. Vestnik Dermatologii i Venerologii 2014; 4: 94—100. 
Коррекция возрастных изменений кожи шеи является актуальной и востребованной в современной косметологии [1]. Проведение косметических процедур в данной области сопряжено с рядом технических сложностей, обусловленных прежде всего ее анатомофизиологическими особенностями [2]. Подчеркивают, что все воздействия должны носить максимально щадящий характер, а тактика лечения - быть максимально консервативной [2, 3].

В настоящее время в распоряжении косметологов находится достаточно большое количество методик, позволяющих эффрективно и бережно воздействовать на возрастные изменения кожи шеи. Такие методы, как ботулинотерапия, биоревитализация, инъекционная контурная пластика, давно уже стали «классикой» современной косметологии [2, 4]. Особую популярность приобретают эффективные малоинвазивные методы коррекции в связи с их относительной технической простотой и коротким реабилитационным периодом. Наиболее широкое распространение среди таких процедур приобретают щадящие лазерные методики [1-3], в частности неабляционное фракционное лазерное воздействие, или фрракционный фототермолиз (ФФ) [3, 5]. Суть этого метода заключается в создании в коже многочисленных зон теплового повреждения контролируемой ширины, глубины и плотности, это позволяет эффективно бороться с возрастными изменениями, возникающими в верхних слоях кожи (расширенными устьями сальноволосяного аппарата, нарушениями пигментации, морщинами, снижением вязкоэластических свойств дермы). Термически поврежденный коллаген в «микротермальных лечебных зонах» полностью обновляется в течение 3 мес. после воздействия [6]. Накапливаются сведения об эфрфективности указанного метода, но результаты наблюдений в основном касаются кожи лица $[7,8]$. Рядом авторов отмечено улучшение упругоэластических свойств кожи, отсутствие отрицательного влияния лазера на параметры увлажненности, обнаружено уменьшение глубины периорбитальных и периоральных морщин, уменьшение гиперпигментации и ширины устьев сальноволосяного аппарата, улучшение равномерности тона и текстуры кожи, шероховатости и сияние кожи [3, 6-9]. Вместе с тем не изучены преимущества и ограничения для применения данной технологии в области шеи, в том числе и в разных возрастных группах.

Цель исследования: научное обоснование применения ФФ для коррекции возрастных изменений кожи шеи у женщин в различных возрастных группах.

\section{Материал и методы}

Под наблюдением находились 60 женщин в возрасте 40-60 лет, обратившихся за косметологической помощью. Пациентки подписали добровольное информированное согласие на участие в исследовании. Для оценки конечного результата процедур ФФ в разных возрастных периодах пациентки были раз- делены на две группы: 1-я - 40-49 лет (30 женщин), 2-я - 50-60 лет (30 женщин).

Всем пациенткам проводилась процедура фрракционного фототермолиза области шеи (аппарат Fraxel re:store $®$ DUAL, США) с помощью эрбиевого (20 мДж: 5-й уровень лечения - 8 пассов) и тулиевого (20 мДж: 5-й уровень лечения - 8 пассов) лазеров. Схема воздействия была следующей: 4 последовательных пасса с использованием длины волны 1550 нм (эрбий) + 4 пасса с использованием длины волны 1927 нм (тулий). За 1 ч. до процедуры использовалась местная анестезия гелем MesoNUMB (бензокаин 20\%, лидокаин 6\%, тетракаин 4\%, производитель Mesodermal, США).

Клиническую оценку результатов процедур врач и пациент проводили с использованием международной шкалы Global Aesthetic Improvement Scale (GAIS) от 0 до 3 баллов [9].

Каждой пациентке проводилась комплексная неинвазивная функциональная диагностика кожи шеи до процедуры, через 1 нед. и 1 мес. после процедуры с помощью полифункционального диагностического аппарата Aramo TS (Южная Корея). Исследовались следующие параметры: увлажненность, гладкость (рельеф) кожи, ширина пор (устьев сально-волосяного аппарата), выраженность пигментации, глубина и ширина морщин.

Статистический анализ полученных результатов осуществлялся с использованием программы для статистической обработки SPSS Statistics 20.0. Все значения признаков исследовались на согласованность с нормальным (гауссовским) распределением с использованием критерия Колмогорова - Смирнова. Распределение выборки признавалось нормальным при Sig $\geq 0,01$. Для нормально распределенных признаков поиск отличий осуществлялся при помощи критерия Стьюдента. Если распределение не было согласовано с нормальным, применялся критерий Манна - Уитни. Различие принималось статистически значимым, если р-значение соответствующего критерия было строго меньше 0,05. Данные описывались в виде среднего значения и стандартной ошибки среднего значения $(M \pm m)$.

\section{Результаты}

Анализ клинической картины возрастных изменений кожи шеи до процедуры показал, что в 1-й возрастной группе у $61 \%$ (18) пациенток было выявлено умеренное снижение тургора кожи и ее эластичности, отмечен «избыток» кожи и морщинистость в области шеи и подподбородочной зоне. При этом шейно-подбородочный угол был хорошо выражен, скопления жировой клетчатки отсутствовали, при пальпации определялся удовлетворительный тонус m. platysma. Данные изменения соответствовали I стадии старения кожи шеи по R. Bazin и соавт. (2007) [10]. У 39\% (12) пациенток определялся кожный птоз без излишнего скопления 
подкожного жира с появлением или усугублением горизонтальных складок шеи (II стадия старения), также выявлены солнечное лентиго (у 7) и мелазма (у 10).

Во 2-й возрастной группе у 56\% (17) пациенток изменения кожи соответствовали II стадии старения кожи шеи, а у остальных 13 человек обнаружена выраженная аккумуляция подкожного жира с деформацией формы шеи и выраженные вертикальные тяжи платизмы с аккумуляцией подкожного жира и без него (III и IV стадии старения). Кроме того, у 26 пациенток 2-й возрастной подгруппы были обнаружены такие кожные проявления, как солнечное лентиго (у 6), мелазма (у 13), единичные папилломы (у 15).

Отмечена в целом хорошая переносимость процедур в обеих группах, инфекционных осложнений выявлено не было. У всех пациенток после ФФ отмечались незначительные ощущения дискомфорта (покалывание, жжение) различной степени выраженности. Вместе с тем использование лазера не вызывало выраженного дискомфорта и не сказывалось на повседневной активности пациенток. Отмечались эритема и отек в месте обработки кожи продолжительностью 3,47 \pm 0,86 сут. у пациенток 1-й группь и 3,87 \pm 0,9 сут. - у пациенток 2-й группы, а также мелкопластинчатое шелушение - 7,57 \pm 0,94 и 8,5 $\pm 0,97$ сут. соответственно.

Клинические изменения через 1 мес. после процедуры ФФ проявлялись уменьшением выраженности горизонтальных морщин кожи шеи, улучшением и вы- равниванием цвета и рельефа кожи у пациенток обеих групп. У пациенток 1-й группы проявления кожного птоза стали менее выраженными, а во 2-й группе сохранялись деформация кожи шеи и кожный птоз. Наблюдалось также побледнение лентиго и мелазмы, последнее - более выраженное у лиц 1-й группы.

Оценка пациентками эффректа процедур с использованием шкалы GAIS показала, что 70\% женщин 1-й группы и 60\% 2-й были полностью удовлетворены или довольны результатом, но хотели бы немного улучшить (рис. 1). Большинство пациенток 1-й группы (27 из 30) и 2-й группы (25 из 30), оценившие результат лечения как хороший, выразили желание продолжить курс процедур. Оценка процедуры врачом практически совпала с мнением самих пациенток: 63\% женщин в 1-й группе и 53\% - во 2-й были полностью удовлетворены или довольны результатом, но хотели бы немного улучшить (рис. 2).

Неинвазивная функциональная диагностика состояния кожи шеи, проведенная до и после процедур $Ф Ф$, показала положительную динамику большинства параметров (см. таблицу).

Через 1 нед. после ФФ отмечено негативное изменение показателей увлажненности, гладкости кожи в обеих группах, причем более значимое - у лиц 2-й группы. Из таблицы видно, что статистически значимо увеличились показатели размеров устьев сально-волосяного аппарата, пигментации и глубины морщин в обеих возрастных группах, причем более
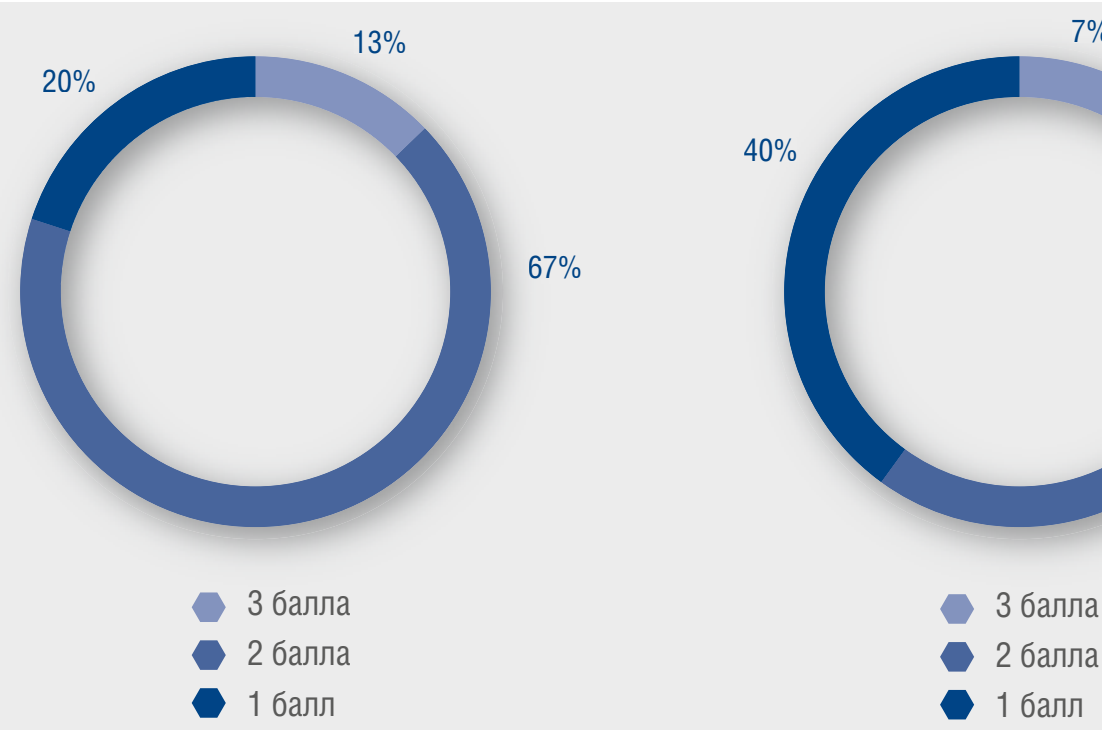

Рис. 1. Оценка результатов процедуры пациентами:

при оценке результатов процедуры пациентом указывался один из следующих пунктов: 3 балла — полностью удовлетворен результатом; 2 - доволен результатом, но хочется немного улучшить; 1 - улучшение незначительное, желательна дополнительная коррекция; 0 - без изменений; $(-1)$ - состояние хуже, чем до проведения процедуры 


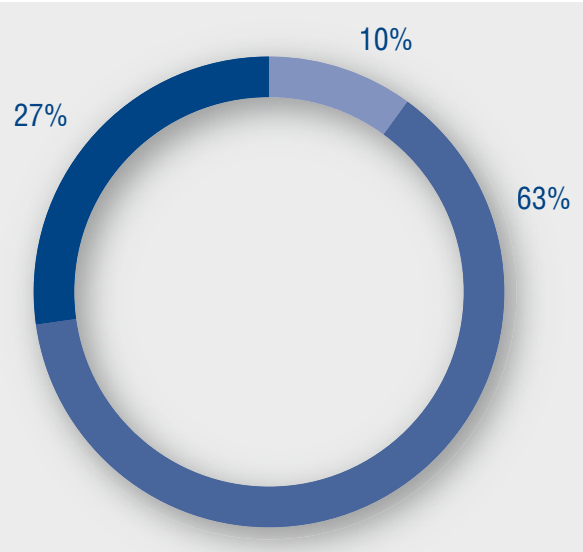

3 балла

2 балла

1 балл

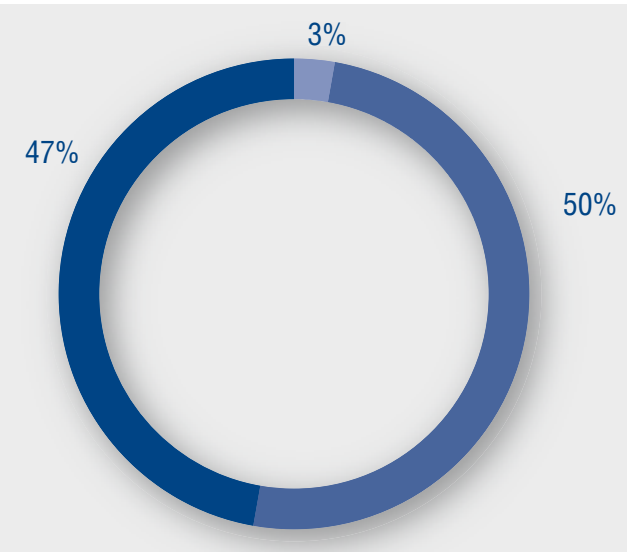

3 балла

2 балла

1 балл

Рис. 2. Оценка результатов процедуры врачом:

при оценке результатов воздействия врачом указывался один из следующих пунктов: 3 балла - оптимальный косметический результат; 2 - значительное улучшение, но не полная коррекция; 1 - улучшение, но необходима дополнительная коррекция; 0 - нет изменений, состояние такое же, как до процедуры; (-1) - ухудшение по сравнению с исходным состоянием

Таблица

Динамика показателей увлажненности, рельефа, ширины устьев сально-волосяного аппарата, пигментации, глубины и ширины морщин кожи до и после процедур ФФ

\begin{tabular}{|c|c|c|c|c|}
\hline \multirow{2}{*}{ Показатель } & \multirow{2}{*}{ 1-я группа $(n=30)$} & \multirow{2}{*}{ 2-я группа $(n=30)$} & \multicolumn{2}{|c|}{ Достоверность ( $p)$} \\
\hline & & & 1-я группа & 2-я группа \\
\hline \multicolumn{5}{|l|}{ Увлажненность: } \\
\hline до процедур & $34,1 \pm 2,35(30-40)$ & $33,83 \pm 2,29(29-39)$ & & \\
\hline через 1 нед. & $31,1 \pm 3,16(24-37)$ & $28,67 \pm 3,15(22-35)$ & $<10^{-5}$ & $<10^{-9}$ \\
\hline через 1 мес. & $35,5 \pm 2,58(32-41)$ & $34,5 \pm 2,29(29-39)$ & $<10^{-7}$ & 0,01 \\
\hline \multicolumn{5}{|l|}{ Гладкость: } \\
\hline до процедур & $36,1 \pm 5,23(27-52)$ & $37,53 \pm 5,47(22-47)$ & & \\
\hline через 1 нед. & $31,47 \pm 3,66(24-38)$ & $31,47 \pm 5,75(17-41)$ & $<10^{-6}$ & $<10^{-9}$ \\
\hline через 1 мес. & $38,3 \pm 5,5(28-52)$ & $42,17 \pm 5,64(31-55$ & 0,002 & $<10^{-8}$ \\
\hline \multicolumn{5}{|l|}{ Поры: } \\
\hline до процедур & $16,53 \pm 9,69(5-52)$ & $17,27 \pm 8,65(6-39)$ & & \\
\hline через 1 нед. & $19,53 \pm 10,7(7-60)$ & $21,6 \pm 8,61(8-43)$ & 0,004 & $<10^{-7}$ \\
\hline через 1 мес. & $13,53 \pm 9,42(4-49)$ & $14,97 \pm 8,28(4-37)$ & $<10^{-5}$ & $<10^{-4}$ \\
\hline \multicolumn{5}{|l|}{ Пигментация: } \\
\hline до процедур & $16 \pm 10,65(2-53)$ & $21,87 \pm 11,79(4-40)$ & & \\
\hline через 1 нед. & $23,43 \pm 12,06(6-56)$ & $30,57 \pm 13,79(10-56)$ & $<10^{-9}$ & $<10^{-11}$ \\
\hline через 1 мес. & $11,43 \pm 6,69(2-27)^{\prime}$ & $17,5 \pm 9,6(3-34)$ & 0,001 & $<10^{-7}$ \\
\hline \multicolumn{5}{|l|}{ Глубина морщин: } \\
\hline до процедур & $32,4 \pm 7,02(14-44)$ & $34,7 \pm 7,78(19-48)$ & & \\
\hline через 1 нед. & $37,07 \pm 8,36(15-50)$ & $40,33 \pm 8,55(26-54$ & $<10^{-10}$ & $<10^{-12}$ \\
\hline через 1 мес. & $26,33 \pm 7,14(11-39)$ & $30,4 \pm 7,6(18-45)$ & $<10^{-8}$ & $<10^{-7}$ \\
\hline \multicolumn{5}{|l|}{ Ширина морщин: } \\
\hline до процедур & $0,17 \pm 0,03(0,13-0,29)$ & $0,17 \pm 0,03(0,13-0,27)$ & & \\
\hline через 1 нед. & $0,17 \pm 0,03(0,14-0,29)$ & $0,18 \pm 0,03(0,14-0,28)$ & 1 & $<10^{-8}$ \\
\hline через 1 мес. & $0,14 \pm 0,03(0,1-0,27)$ & $0,15 \pm 0,03(0,11-0,21)$ & $<10^{-5}$ & $<10^{-7}$ \\
\hline
\end{tabular}


значимое увеличение этих показателей отмечалось у пациенток 2-й группы. При оценке динамики показателя ширины морщин установлено, что у женщин 1-й группы значимых изменений не произошло, а у пациенток старшей возрастной группы этот показатель достоверно увеличился.

Через 1 мес. после ФФ зарегистрировано увеличение показателя увлажненности относительно исходного уровня, более достоверное в 1-й группе. В 1-й возрастной группе увеличение гладкости было, согласно р-значению, статистически менее значимым, чем во 2-й. Примечательно, что прирост показателя гладкости был выше во 2-й группе (на 5 ед. измерения) по сравнению с 1-й группой (на 2 ед. измерения). Уменьшение размеров устьев сально-волосяного аппарата и глубины морщин было статистически более значимо для 1-й группы, чем для 2-й. Зарегистрировано достоверное уменьшение пигментации. Пигментация кожи уменьшилась на 29\% в 1-й группе и лишь на 20\% - во 2-й. Ширина морщин снизилась более значимо у пациенток 2-й группы по сравнению с 1-й (см. таблицу).

В целом следует подчеркнуть, что через 1 нед после процедур ФФ отмечено ухудшение ряда функциональных параметров кожи, более выраженное во 2-й возрастной группе. Через 1 мес. показатели гладкости $\left(p<10^{-8}\right)$, ширины морщин $\left(p<10^{-7}\right)$ во 2-й группе изменились более достоверно, чем в 1-й группе $\left(p=0,002 ; p=0,001 ; p<10^{-5}\right)$. Позитивная динамика показателей увлажненности кожи шеи, пигментации, ширины сально-волосяного аппарата и глубины морщин была более значимой в 1-й группе $\left(p<10^{-7} ; p=0,001 ; p<10^{-5} ; p<10^{-8}\right)$.

Корреляционный анализ показал, что с увеличением возраста наблюдалось уменьшение выраженности увлажненности кожи шеи в результате процедуры $(r=-0,38, p<0,01)$. Кроме того, зарегистрирована отрицательная корреляция между возрастом пациентки и выраженностью уменьшения глубины морщин $(r=-0,33, p<0,05)$, но положительная между возрастом и увеличением гладкости кожи в результате процедуры $(r=0,26, p<0,05)$. Отмечена также корреляция между увеличением увлажненности и уменьшением глубины морщин через месяц после процедуры $(r=0,28, p<0,05)$ для всех женщин, получавших ФФ.

\section{Обсуждение}

Полученные нами данные указывают на положительный эстетический результат процедуры ФФ в области кожи шеи, что проявляется уменьшением выраженности признаков возрастных изменений кожи и оптимизацией фрунциональных параметров кожи.

Наши данные соотносятся с результатами других исследований [7]. В частности, D. Manstein и соавт. (2004) в исследовании периорбитальной зоны у 30 добровольцев продемонстрировали и убедительно до- казали клинически значимый эффрект коррекции морщин и общего омоложения кожи лица [5].

Нами показана безопасность методики ФФ, что также соответствует другим публикациям. В частности, в исследовании Z. Rahman и соавт. (2006) отмечены положительный эффект и безопасность при лечении мелазмы, удалении периорбитальных морщин, послеоперационных рубцов и рубцов после акне, а также пигментных пятен. Безопасность методики продемонстрирована также D. Behroozan и соавт. (2006) при коррекции пойкилодермы Сиватта [12]. Подчеркивают, что использование передовых технологий, таких как неаблятивное фракционное ремоделирование с помощью лазера Fraxel re:store ${ }^{\mathrm{TM}}$, обеспечивает эффрективную доставку энергии лазера в ткани с минимальным риском развития побочных эффектов и осложнений [11].

Продолжительность существования эритемы, оте-ка и шелушения у пациенток в нашем исследовании является ожидаемой и объясняется результатами серии гистологических исследований, проведенных H. Laubach и соавт. (2005). Авторы показывают, что при использовании неаблятивного ФФ области предплечья целостность базального слоя эпидермиса восстанавливается в течение 24 ч., а полная регенерация эпителия достигается к 7-м суткам [6]. Непродолжительную эритему и отек (1-3 сут. при обработке зоны лица) после ФФ отмечают и другие авторы [14]. Специалисты подчеркивают, что в области шеи процедуры должны проводиться в более щадящем режиме, чем в области лица, и требуют более продолжительной реабилитации [4]. Полученные данные указывают на важность бережного очищения и увлажнения кожи на этапе реабилитации.

Безусловно, как и другие неаблятивные методы, ФФ требует проведения нескольких процедур. По опыту G. Roy и соавт. (2006), при коррекции морщин на лице таких же результатов можно добиться, проведя лишь одну процедуру с использованием Er: YAG или $\mathrm{CO}_{2}$-аблятивного лазера. Однако после обработки $\mathrm{Er}$ : YAG или $\mathrm{CO}_{2}$-лазером реабилитационный период составляет от 10 до 30 сут. и имеется более высокий риск осложнений [8]. Продемонстрирована эквивалентность конечных эстетических результатов неаблятивного ФФ и аблятивных лазеров, за исключением эффекта на глубокие морщины [13]. Представленные данные подтверждают перспективность использования ФФ для коррекции возрастных изменений кожи шеи.

Результаты корреляционного анализа продемонстрировали обратную зависимость между возрастом пациентки и показателями оптимизации увлажненности и глубины морщин после процедур. Вместе с тем выявлена положительная зависимость между возрастом и гладкостью кожи после процедуры ФФ. Данный фракт следует учитывать профессионалам при прогнозе результатов процедур в более старших возрастных группах. Это объясняется менее выраженным клиническим эффректом омоложения у пациенток в пери- 
менопаузе в связи с низкими регенераторными свойствами кожи [15]. Тот факт, что увлажненность кожи коррелирует с показателем глубины морщин, еще раз подтверждает целесообразность увлажняющих средств или процедур для улучшения эстетического восприятия состояния кожи [1].

\section{Заключение}

1. Процедура фрракционного фрототермолиза в области кожи шеи безопасна и приводит к позитивному клиническому эффекту у женщин в возрасте 40-60 лет, что проявляется уменьшением выраженности горизонтальных морщин, улучшением и выравниванием цвета и рельефа кожи, уменьшением интенсивности пигментации мелазмы и лентиго. Суммарный клинический эффект после процедуры фракционного фототермолиза более выражен у женщин в возрасте 40-49 лет по сравнению с женщинами в возрасте 50-60 лет.
2. Фракционный фрототермолиз существенно оптимизирует такие показатели функционального состояния кожи, как увлажненность, рельеф, ширина устьев сально-волосяного аппарата, пигментация, глубина и ширина морщин.

3. Через 1 нед. после процедуры фрракционного фрототермолиза сохраняется шелушение кожи и характерно ухудшение всех функциональных параметров, более выраженное у женщин старшей возрастной группы.

4. Через 1 мес. после процедуры фракционного фототермолиза для женщин 40-49 лет характерно более значимое улучшение показателей увлажненности, ширины сально-волосяного аппарата, глубины морщин и пигментации.

5. Через 1 мес. после процедуры фрракционного фототермолиза для женщин 50-60 лет характерно более значимое улучшение показателей гладкости и ширины морщин. І

\section{Литература}

1. Amelina P.O., Araviijskaja E.R. Dermatokosmetologicheskij podhod k kozhe oblasti shei. V kn.: Aravijskaja E.R., Sokolovskij E.V. Rukovodstvo po dermatokosmetologii. Foliant, SPb, 2008. s. 286-291. [Амелина П.О., Аравийская Е.Р. Дерматокосметологический подход к коже области шеи. В кн.: Аравийская Е.Р., Соколовский Е.В. Руководство по дерматокосметологии. СПб, Фолиант, 2008. с. 286—291.]

2. Kirsanova L.V., Aravijskaja E.A., Sokolovskij E.V., Bogatenkov A.I. Vozrastnye izmenenija oblasti shei i metody kosmetologicheskoj korrekcii (chast' 1). Vestn jestet med 2012; 11 (2): 52—58. [Кирсанова Л.В., Аравийская Е.А., Соколовский Е.В., Богатенков А.И. Возрастные изменения области шеи и методы косметологической коррекции (часть 1). Вестн эстет мед 2012; 11 (2): 52-58.]

3. Kirsanova L.V., Aravijskaja E.A., Sokolovskij E.V. Sokolov G.N., Bogatenkov A.I. Vozrastnye izmenenija oblasti shei i metody ih kosmetologicheskoj korrekcii (chast' 2). Vestn jestet med 2012; 11 (3): 46-54. [Кирсанова Л.В., Аравийская Е.А., Соколовский Е.В., Соколов Г.Н., Богатенков А.И. Возрастные изменения области шеи и методы их косметологической коррекции (часть 2). Вестн эстет мед 2012; 11 (3): 46-54.]

4. Zhukova I., Lashhinina E., Demidova L «3 D-mezoniti». Jesteticheskaja medicina 2013; 12 (3): 327-333. [ЖYкова И., Лащинина Е., Демидова Л. «З D-мезонити». Эстетическая медицина 2013; 12 (3): 327-333.]
5. Imaeva N. Morshhiny shei i dekol'te: «delikatnye» zony, shhadjashhee vozdejstvie. Kosmetik international 2013; (5): 54-57. [Имаева Н. Морщины шеи и декольте: «деликатные» зоны, щадящее воздействие. Kosmetik international 2013; (5): 54—57.]

6. Laubach H.J., Tannous Z., Anderson R.R. Skin Responses to Fractional Photothermolysis. Lasers Surg. Med 2005.

7. Manstein D., Hereon G.S., Sink R.K., Tanner H., Anderson R.R. Fractional photothermolysis: a new concept for cutaneous remodeling using microscopic patterns of thermal injury. Lasers Surg Med 2004; 34 (5): $426-438$.

8. Goldberg D.D. Lazernaja shlifovka kozhi. V kn.: Lazero- i svetolechenie. Moskva: Rid Jelsiver (sovmestno s izdatel'stvom «Prakticheskaja Medicina»); 2010. [Голдберг Д.Д. Лазерная шлифовка кожи. В кн.: Лазеро- и светолечение. М.: Рид Элсивер (совместно с издательством «Практическая Медицина»); 2010.]

9. Panova O.S. Gubanova E.I. D'jachenko Ju. Ju Vlijanie frakcionnogo fototermoliza na biofizicheskie parametry kozhi. Prospektivnoe kliniko-instrumental'noe issledovanie. Jesteticheskaja medicina 2010; (1): 85—93. [Панова О.С., Губанова Е.И., Дьяченко Ю.Ю. Влияние фракционного фототермолиза на биофиизические параметры кожи. Проспективное клиникоинструментальное исследование. Эстетическая медицина 2010; (1): 85—93.]
10. Bazin R., Doublet E. Skin Aging Atlas. Caucasian type. Med'com publishing 2007; (1): 58-66.

11. Rahman Z., Jiang K., Chan K. Nonablative Fractional Resurfacing Proven Efective with the Fraxel re:store ${ }^{\mathrm{TM}}$ Laser. 2006; Sept.

12. Behroozan D.S., Goldberg L.H., Glaich A.S., Dai T., Friedman P.M. Fractional photothermolysis for treatment ofpoikiloderma ofcivatte. Dermatol Surg 2006; 32 (2): 298-301.

13. Geronemus R.G. Fractional Photothermolysis: Current and Future Applications. Lasers Surg. Med 2006; (38): 169-176.

14. Wanner M., Tanzi E.L., Alster T.S. Fractional photothermolysis: treatment of facial and nonfacial cutaneous photodamage with a 1, 550-nm erbium-doped fiber laser. Dermatol Surg 2007; 33 (1): 23-8.

15. Morgulis Ju.V., Potekaev N.N., Korsunskaja I.M. Sostojanie kozhi u zhenshhin posle hirurgicheskoj menopauzy i metody ee terapevticheskoj korrekcii. Rus med zhurn 2008; 16 (19): 1—- 5. [Моргулис Ю.В. Потекаев Н.Н., Корсунская И.М. Состояние кожи у женщин после хирургической менопаузы и методы ее терапевтической коррекции. Рус мед журн 2008; $16(19): 1-5$.

об авторах:

Л.В. Кирсанова — врач-дерматолог, косметолог, Санкт-Петербургский институт красоты

Е.Р. Аравийская - Д.м.н., профессор кафедры дерматовенерологии с клиникой ГБОУ ВПО «СПбГМУ им. академика

И.П. Павлова» Минздрава России

Е.В. Соколовский — д.м.н., профессор, зав. кафедрой с клиникой ГБОУ ВПО «СПбГМУ им. академика И.П. Павлова» Минздрава России Г.Н. Соколов — к.м.н., доцент кафедры дерматовенерологии с клиникой ГБОУ ВПО «СПбГМУ им. академика И.П. Павлова» Минздрава России

А.И. Богатенков — врач-дерматовенеролог, косметолог, главный врач клиник медицинской косметологии Санкт-Петербургский институт красоты 